\title{
Bronchopulmonary dysplasia and neurodevelopmental outcome in extremely preterm neonates
}

\author{
J. K. Trittmann • L. D. Nelin • M. A. Klebanoff
}

Received: 30 January 2013 /Revised: 16 April 2013 / Accepted: 18 April 2013 /Published online: 5 May 2013

(C) The Author(s) 2013. This article is published with open access at Springerlink.com

\begin{abstract}
We tested the hypothesis that the use of supplemental oxygen $\left(\mathrm{sO}_{2}\right)$ at discharge from the NICU in extremely preterm neonates is associated with a greater risk of neurodevelopmental impairment (NDI) at 18 months corrected gestational age (CGA) than the risk of NDI of those neonates discharged in room air. Four hundred twentyfour charts were retrospectively reviewed from infants born at $<27$ weeks and transferred to Nationwide Children's Hospital from December 1, 2004 to June 14, 2010. Use of $\mathrm{sO}_{2}$ was evaluated on day of life (dol) 28, at 36 weeks postmenstrual age (PMA), and at discharge. Logistic regression was used to identify postnatal risk factors associated with $\mathrm{sO}_{2}$ at discharge and NDI. At dol 28, $96 \%$ of surviving patients received $\mathrm{sO}_{2}$, and therefore had bronchopulmonary dysplasia (BPD) by definition from a National Institutes of Child Health and Human Development workshop. At 36 weeks PMA, $89 \%$ continued on $\mathrm{sO}_{2}$ (moderate/severe BPD), and at discharge, $74 \%$ continued on $\mathrm{sO}_{2}$. When factors associated with NDI were examined, the need for mechanical ventilation $\geq 28$ days $(\operatorname{adjOR}=3.21, p=0.01)$, grade III-IV intraventricular hemorrhage (IVH) (adjOR= $4.61, p<0.01$ ), and discharge at $>43$ weeks PMA (adjOR $=$ $2.12, p=0.04)$ were the strongest predictors of NDI at 18 months CGA. There was no difference in Bayley Scales of Infant Development, third edition composite scores between patients with no/mild BPD and patients with moderate/severe BPD (cognitive $p=0.60$, communication $p=0.53$, motor $p=0.19$ ) or those scores between patients on and off oxygen at discharge (cognitive $p=0.58$, communication $p=0.70$, motor $p=0.62$ ). Conclusions: The need for
\end{abstract}

J. K. Trittmann $(\varangle) \cdot$ L. D. Nelin $\cdot$ M. A. Klebanoff

Ohio Perinatal Research Network, Center for Perinatal Research,

The Research Institute at Nationwide Children's Hospital,

Department of Pediatrics, The Ohio State University College of

Medicine, 700 Children's Drive, Research Building III, WB 5245,

Columbus, OH 43205, USA

e-mail: jennifer.trittmann@nationwidechildrens.org
$\mathrm{sO}_{2}$ at discharge is not associated with an increased risk of NDI in these patients. The strongest predictors of poor neurodevelopmental outcome in this population were prolonged positive pressure support, grade III-IV IVH, and discharge at $>43$ weeks PMA.

Keywords Mechanical ventilation · Supplemental oxygen · Very low birth weight · Intraventricular hemorrhage .

Necrotizing enterocolitis

$\begin{array}{ll}\text { Abbreviations } \\ \mathrm{BPD} & \text { Bronchopulmonary dysplasia } \\ \mathrm{dol} & \text { Day of life } \\ \mathrm{IVH} & \text { Intraventricular hemorrhage } \\ \mathrm{NEC} & \text { Necrotizing enterocolitis } \\ \mathrm{NCH} & \text { Nationwide Children's Hospital } \\ \mathrm{PMA} & \text { Post-menstrual age } \\ \mathrm{sO}_{2} & \text { Supplemental oxygen }\end{array}$

\section{Introduction}

Bronchopulmonary dysplasia (BPD) is the most common chronic lung disease affecting preterm infants, and the incidence of BPD is inversely related to gestational age [37]. In 1967, Northway first described BPD as a requirement for supplemental oxygen $\left(\mathrm{sO}_{2}\right)$ at day of life (dol) 28 with chest $\mathrm{X}$-ray findings demonstrating fibrosis and collapse surrounded by areas of marked hyperinflation [26]. Over the decades, a "new" BPD has emerged that is characterized by fewer and larger alveoli, as well as decreased pulmonary microvasculature development $[11,18,20,35]$. The emergence of "new" BPD and the improved survival of patients born at extremely early gestational ages led to a new definition of BPD from a National Institutes of Child Health and Human Development (NICHD) workshop [18]. Using this definition and the inverse relationship to gestational age, the 
incidence of BPD in the extremely preterm infant is very high. For example, Farstad et al. recently reported an incidence of $86 \%$ in a Norwegian cohort of patients born between 22 and 27 completed weeks of gestation [12]. Given the high incidence of BPD in this population, we examined the use of $\mathrm{sO}_{2}$ at discharge to determine incidence and factors associated with $\mathrm{sO}_{2}$ use at discharge. Since BPD has been associated with poor neurodevelopmental outcome $[3,14,17,27-29,31-34,38]$, we tested the hypothesis that the use of $\mathrm{sO}_{2}$ at discharge from the NICU in extremely preterm neonates is associated with a greater risk of neurodevelopmental impairment (NDI) at 18 months corrected gestational age (CGA).

\section{Methods}

This study was approved by the Institutional Review Board of the Nationwide Children's Hospital ( $\mathrm{NCH}$ ). This is a retrospective observational study. Charts were reviewed and data obtained from all 424 patients who were born at $<27$ weeks gestation and transferred to the $\mathrm{NCH}$ NICU between December 1, 2004 and June 14, 2010. Only patients who survived, were not transferred, and had available data at 28 days were included in the study (345 patients). The NCH NICU is an all referral (i.e., no inborn patients) level IV [1] center in Columbus, Ohio, USA, which receives referrals from 22 hospitals in Central Ohio. The NICU Small Baby Pod at NCH is a dedicated space and nursing staff which allows for an interdisciplinary, standardized approach to the care of the extremely preterm neonate born at $<27$ completed weeks gestational age [24].

NICU data were abstracted from charts by trained personnel and entered into the Small Baby Database, which contains basic demographic information and details of the hospital course for each patient admitted to the Small Baby Pod at NCH. Gestational age was determined by prenatal ultrasound when available and confirmed by Ballard Score. Since $\mathrm{NCH}$ is an all referral hospital, maternal data were limited. For example, the presence of chorioamnionitis was not reliably available on all patients. Oxygen status was assessed at dol 28, 36 weeks post-menstrual age (PMA), and at discharge. The attending physician prescribed the $\mathrm{sO}_{2}$ for these patients. At the time this study was conducted, there was not a policy to include an oxygen challenge test at 36 weeks and supplemental oxygen was as prescribed by the attending neonatologist. BPD was defined as a need for $\mathrm{sO}_{2}$ at dol 28 and then stratified based on the use of $\mathrm{sO}_{2}$ at 36 weeks PMA as per the definition from a NICHD workshop [18], where mild disease is defined as no $\mathrm{sO}_{2}$ at 36 weeks PMA, moderate $\mathrm{BPD}$ is defined as an $\mathrm{sO}_{2}$ requirement of $<30 \%$ at 36 weeks PMA, and severe BPD is defined as an $\mathrm{sO}_{2}$ requirement of $>30 \%$ and/or positive pressure support at 36 weeks PMA. Comorbidities were assessed, including necrotizing enterocolitis (NEC) and intraventricular hemorrhage (IVH). Short-term outcome measurements included $\mathrm{sO}_{2}$ at discharge and hospital length of stay. Longer term outcomes included 18-month corrected composite scores on the Bayley Scales of Infant Development, third edition (BSID-III) assessment. Patients without BPD were evaluated at routine follow-up visits in the neonatology outpatient clinic and patients with BPD were evaluated at the Comprehensive Center for BPD at NCH [30]. NDI was defined as any Bayley composite score (cognitive, communication, or motor) $<80$ or cerebral palsy $[19,22,39]$.

\section{Statistical analysis}

Patients who were discharged to home (i.e., survived and not transferred to another institution) were divided into two groups. The first group consisted of those patients who did not require $\mathrm{sO}_{2}$ at discharge. The second group consisted of those patients who required $\mathrm{sO}_{2}$ at discharge. Continuous variables, including BSID-III scores, were compared between groups using Student's $t$ test, and categorical variables, including NDI, were compared by $\chi^{2}$ analysis. Logistic regression was used to model those factors potentially associated with $\mathrm{sO}_{2}$ at discharge and NDI. Clinical characteristics were chosen based on a priori interest and included $\leq 24$ weeks gestational age, birth weight $\leq 700 \mathrm{~g}$, Apgar score at $5 \mathrm{~min} \leq 3$, admission $\operatorname{dol} \geq 7, \mathrm{CPAP} \geq 28$ days, mechanical ventilation $\geq 28$ days, PDA ligation, surgical NEC, grade III-IV IVH, discharge $>43$ weeks PMA, moderate-severe $\mathrm{BPD}$, and $\mathrm{sO}_{2}$ at discharge. Unadjusted and adjusted odds ratios for NDI were also calculated for these same clinical characteristics. All analyses were conducted with STATA 12 statistical software (StataCorp. 2011. Stata Statistical Software: Release 12. College Station, TX: StataCorp LP). Boxplots were created using GraphPad Prism version 6.00 for Windows (GraphPad Software, La Jolla California USA, www.graphpad.com). A two-tailed $p$ value of $<0.05$ was considered statistically significant.

\section{Results}

Of the 424 patients admitted to NCH during the time of this study, $16(4 \%)$ transferred prior to dol 28, 55 (13\%) died prior to dol 28 , and 8 ( $2 \%)$ did not have available data at dol 28 , such that there were 345 eligible patients at dol 28 (Fig. 1). Figure 1 also demonstrates the number of eligible patients at 36 weeks PMA, discharge to home, and at 18month follow-up. It is of interest to note that for this highly vulnerable patient group, the overall mortality rate during the initial NICU stay was $20 \%(86 / 424)$, and most of the 


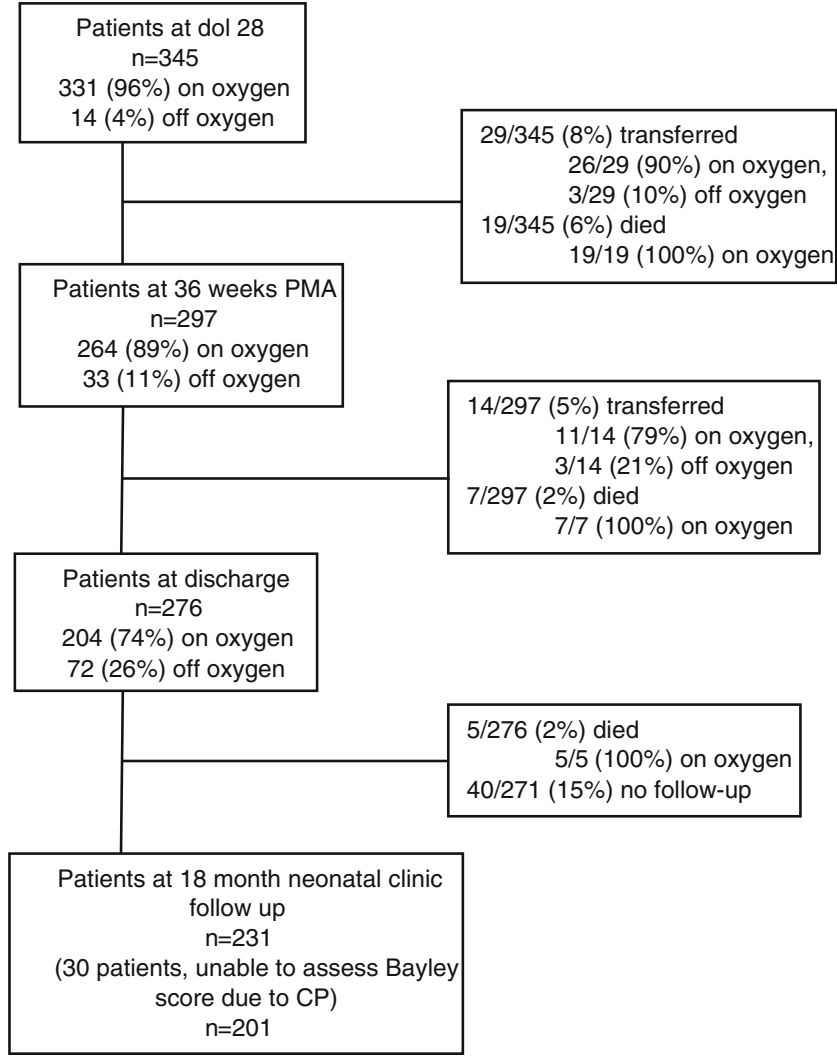

Fig. 1 Patients admitted between December 1, 2004 and June 14, 2010. Three hundred forty-five patients born at $<27$ weeks gestation were eligible for this study on day of life (dol) 28 . At discharge, there remained 276 patients of which $2 \%$ died and $15 \%$ did not return for follow-up at the neonatal clinic. At 18 months corrected gestational age, 30 patients had cerebral palsy $(C P)$ and 201 patients had Bayley scores available for analysis

mortality occurred before dol 28 , resulting in a mortality rate between dol 28 and discharge of $7 \%$. Furthermore, there was no mortality in patients during their initial NICU stay that were successfully weaned off of $\mathrm{sO}_{2}$ from dol 28 until discharge.

Table 1 summarizes $\mathrm{sO}_{2}$ use at dol 28, 36 weeks PMA, and discharge in the extremely preterm infant stratified by gestational age. For the entire group, $96 \%$ of the patients received $\mathrm{sO}_{2}$ at dol $28,89 \%$ continued to receive $\mathrm{sO}_{2}$ at 36 weeks PMA, and $74 \%$ of the patients continued to receive $\mathrm{SO}_{2}$ at discharge. Only $4 \%$ of the patients did not require $\mathrm{sO}_{2}$ at dol 28 and therefore, by $\mathrm{NIH}$ definition, did not have BPD [18]. Even in this extremely preterm population, the use of $\mathrm{sO}_{2}$ at any of the measured time points tended to be greater as gestational age of the patient at birth decreased $(p<0.01)$.

Table 2 summarizes patient characteristics, selected comorbidities, and NDI for this population. Those patients who went home on $\mathrm{sO}_{2}$ were of lower gestational age $(p=0.02)$ and weighed at birth an average of $50 \mathrm{~g}$ less than patients discharged on room air $(p=0.03)$. Patients discharged on $\mathrm{sO}_{2}$ had significantly $(p<0.01)$ more days on mechanical ventilation ( $58 \pm 51$ days) than did patients discharged on room air ( $24 \pm 21$ days). Patients discharged on $\mathrm{sO}_{2}$ had a PDA ligation more often (52 vs. $36 \%, p=0.02$ ) and had less surgical NEC ( 8 vs. $28 \%, p<0.01)$ than did patients discharged on room air. NDI was similar between those discharged on room air and those discharged on $\mathrm{sO}_{2}$ (51 vs. $47 \%, p=0.67$ ).

In the adjusted analysis of $\mathrm{sO}_{2}$ at discharge, patients receiving CPAP for $\geq 28$ days were more likely to go home on oxygen $(\operatorname{adjOR}=2.9,95 \%$ CI 1.4-6.2, $p<0.01)$. Similarly, patients receiving $\geq 28$ days of mechanical ventilation were more likely to receive $\mathrm{sO}_{2}$ at discharge $(\operatorname{adjOR}=7.7$, $95 \%$ CI 2.9-20.5, $p<0.01)$. We also found that there was a significantly $(p<0.01)$ greater proportion of patients in the discharged home on room air group that were ventilated for $\leq 14$ days $(45 \%)$ than in those discharged home on $\mathrm{sO}_{2}$ $(20 \%)$. Patients with surgical NEC were less likely to receive $\mathrm{sO}_{2}$ at discharge $(\operatorname{adjOR}=0.11,95 \%$ CI 0.04 $0.30, p<0.01)$. None of the other factors in Table 2 were significantly associated with $\mathrm{sO}_{2}$ at discharge in the logistic regression model.

In order to further explore the relationship between surgical NEC and $\mathrm{sO}_{2}$ at discharge, we analyzed the characteristics of these 36 patients. The mortality rate (after dol 28) for surgical NEC was 2/36 (6\%). Those surgical NEC patients who were discharged on $\mathrm{sO}_{2}$ had a longer $(p=0.02)$ duration of mechanical ventilation (58 \pm 31 days) than did those surgical NEC patients discharged on room air ( $35 \pm 27$ days). However, patients with surgical NEC who went home on $\mathrm{sO}_{2}$ had a significantly shorter length of stay (surgical NEC home on $\mathrm{sO}_{2} 144 \pm 28$ days vs. surgical NEC home on room air $188 \pm 69$ days, $p=0.02$ ) and their PMA at time of discharge was less $(46 \pm 4$ weeks vs. $53 \pm 10$ weeks, $p<0.01)$ than those patients with surgical NEC who went home on room air.

Of the 276 patients who were discharged alive, 5 subsequently died and 231 ( $85 \%$ of survivors) presented for an 18-month Bayley exam at their routine neonatal clinic follow-up visit. Cerebral palsy was diagnosed in 30/231 $(13 \%)$ of those patients discharged alive who presented for follow-up (Fig. 1). Given that Bayley scores were not assigned for patients with cerebral palsy, Bayley scores were available for 201 patients. Motor scores were not available for three patients and communication scores were not available for two patients, due to inability to perform the test. For the corrected cognitive scores, 54/201 $(27 \%)$ were $<80$; for the corrected communication scores, 65/199 (33\%) were $<80$; and for the corrected motor scores, 62/198 (31\%) were $<80$. There were no significant differences in Bayley scores between those patients with no/mild BPD and moderate/severe BPD (Fig. 2a). Similarly, there were 
Table 1 Supplemental oxygen $\left(\mathrm{sO}_{2}\right)$ use at day of life (dol) 28, 36 weeks post-menstrual age (PMA), and at discharge for patients according to gestational age at birth

\begin{tabular}{lcll}
\hline $\begin{array}{l}\text { Gestational } \\
\begin{array}{l}\text { age } \\
\text { (weeks) }\end{array}\end{array}$ & $\mathrm{sO}_{2}$ at 28 dol $^{\mathrm{a}}$ & $\begin{array}{l}\mathrm{sO}_{2} \text { at } \\
36 \text { weeks } \\
\mathrm{PMA}^{\mathrm{a}}\end{array}$ & $\begin{array}{l}\mathrm{sO}_{2} \text { at } \\
\text { discharge }\end{array}$ \\
\hline $22-23$ & $100 \%(55 / 55)$ & $91 \%(42 / 46)$ & $86 \%(37 / 43)$ \\
24 & $98 \%(95 / 97)$ & $90 \%(76 / 84)$ & $75 \%(56 / 75)$ \\
25 & $95 \%(98 / 103)$ & $91 \%(82 / 90)$ & $74 \%(64 / 86)$ \\
26 & $92 \%(83 / 90)$ & $83 \%(64 / 77)$ & $65 \%(47 / 72)$ \\
Total & $96 \%(331 / 345)$ & $89 \%(264 / 297)$ & $74 \%(204 / 276)$
\end{tabular}

${ }^{a}$ Denominator represents all infants alive and in the NICU at that point in time. Percent (ratio) determined for dichotomous variables.

no significant differences in Bayley scores off and on $\mathrm{sO}_{2}$ at discharge (Fig. 2b).

Table 3 summarizes the unadjusted and adjusted odds ratios for NDI. Unadjusted odds ratios were significant for predicting NDI for those patients born at $\leq 24$ weeks gestational age, birth weight $\leq 700 \mathrm{~g}$, mechanical ventilation $\geq 28$ days, surgical NEC, grade III-IV IVH, and discharge at $>43$ weeks PMA. After adjustment for all the factors in Table 3 , only ventilation for $\geq 28$ days, grade III-IV IVH, and discharge at $>43$ weeks PMA remained significantly associated with NDI. Oxygen at discharge was not predictive of NDI (adjOR 0.67, $p=0.18)$.

\section{Discussion}

In this cohort of infants born at $<27$ weeks gestational age, transferred to an all referral NICU, and surviving to dol 28, the majority of surviving patients had BPD as defined by a $\mathrm{sO}_{2}$ requirement on dol 28. Our data are consistent with a recent study of a national cohort by The Norwegian Extreme
Prematurity Study Group, which found that $86 \%$ of infants born between 22 and 27 weeks gestation had BPD and that $80 \%$ of infants born at 22 to 25 completed weeks gestation had moderate-to-severe BPD [12]. In our retrospective cohort of infants referred to a level IV Children's Hospital NICU, $89 \%$ had moderate-to-severe BPD. Unlike other reported cohorts of extremely preterm infants, our rate of moderate-to-severe BPD is likely influenced by the fact that all of our patients are outborn. Outborn patients are referred from several level III NICUs and include the sickest extremely preterm infants from throughout our region, many of whom are referred when they remain on supplemental oxygen. The NICHD Neonatal Research Network recently reported that $43 \%$ of inborn neonates $<29$ weeks gestation had moderate-to-severe BPD [36]. Given that the incidence of BPD is inversely related to gestational age at birth [11, 12, 18, 20, 26, 35, 37], differences in the gestational age of included infants likely contributes to variation in published rates of moderate-severe BPD.

In our extremely preterm infants who survived to discharge, the vast majority (74 \%) were discharged home on $\mathrm{sO}_{2}$. As expected, those patients requiring $\mathrm{sO}_{2}$ at discharge were born earlier and weighed less at birth than those patients who did not require $\mathrm{sO}_{2}$ at discharge. Patients who went home on $\mathrm{sO}_{2}$ had a longer duration of mechanical ventilation. We found that the use of mechanical ventilation for $\geq 28$ days is the strongest predictor of need for $\mathrm{sO}_{2}$ at time of discharge in these patients. In our patient cohort, there was no difference in length of stay between patients who were discharged on $\mathrm{sO}_{2}$ and those discharged on room air. Therefore, it does not appear that patients were being sent home on $\mathrm{sO}_{2}$ in order to hasten discharge from the NICU.

We were surprised to find that patients with surgical NEC were less likely to receive $\mathrm{sO}_{2}$ at discharge. Therefore, we
Table 2 Supplemental oxygen $\left(\mathrm{sO}_{2}\right)$ use at discharge according to patient characteristics

${ }^{\mathrm{a} A n y}$ Bayley composite score (cognitive, communication, or motor) $<80$ or cerebral palsy

\begin{tabular}{lllll}
\hline Characteristics & $\begin{array}{l}\text { Total } \\
(n=276)\end{array}$ & $\begin{array}{l}\mathrm{No} \mathrm{sO}_{2} \text { at discharge } \\
(n=72)\end{array}$ & $\begin{array}{l}\mathrm{sO}_{2} \text { at discharge } \\
(n=204)\end{array}$ & $p$ value \\
\hline Gestational age (weeks) & $24.7 \pm 1.1$ & $24.9 \pm 1.0$ & $24.6 \pm 1.1$ & 0.02 \\
Birth weight (grams) & $723 \pm 166$ & $760 \pm 159$ & $710 \pm 167$ & 0.03 \\
5-min Apgar score & $6 \pm 2$ & $6 \pm 2$ & $6 \pm 2$ & 0.17 \\
Age on admission (dol) & $11 \pm 12$ & $11 \pm 12$ & $10 \pm 12$ & 0.44 \\
CPAP (days) & $35 \pm 19$ & $31 \pm 16$ & $36 \pm 20$ & 0.06 \\
Mechanical ventilation (days) & $49 \pm 47$ & $24 \pm 21$ & $58 \pm 51$ & $<0.01$ \\
PDA ligation & $48 \%(133 / 276)$ & $36 \%(26 / 72)$ & $52 \%(107 / 204)$ & 0.02 \\
Surgical NEC & $13 \%(36 / 276)$ & $28 \%(20 / 72)$ & $8 \%(16 / 204)$ & $<0.01$ \\
Grade III-IV IVH & $21 \%(59 / 275)$ & $18 \%(13 / 72)$ & $23 \%(46 / 203)$ & 0.41 \\
Length of stay (days) & $146 \pm 61$ & $136 \pm 54$ & $150 \pm 63$ & 0.08 \\
Length of stay (PMA, weeks) & $47 \pm 9$ & $46 \pm 7$ & $47 \pm 9$ & 0.19 \\
Neurodevelopmental Impairment & $50 \%(115 / 231)$ & $47 \%(26 / 55)$ & $51 \%(89 / 176)$ & 0.67 \\
\hline
\end{tabular}



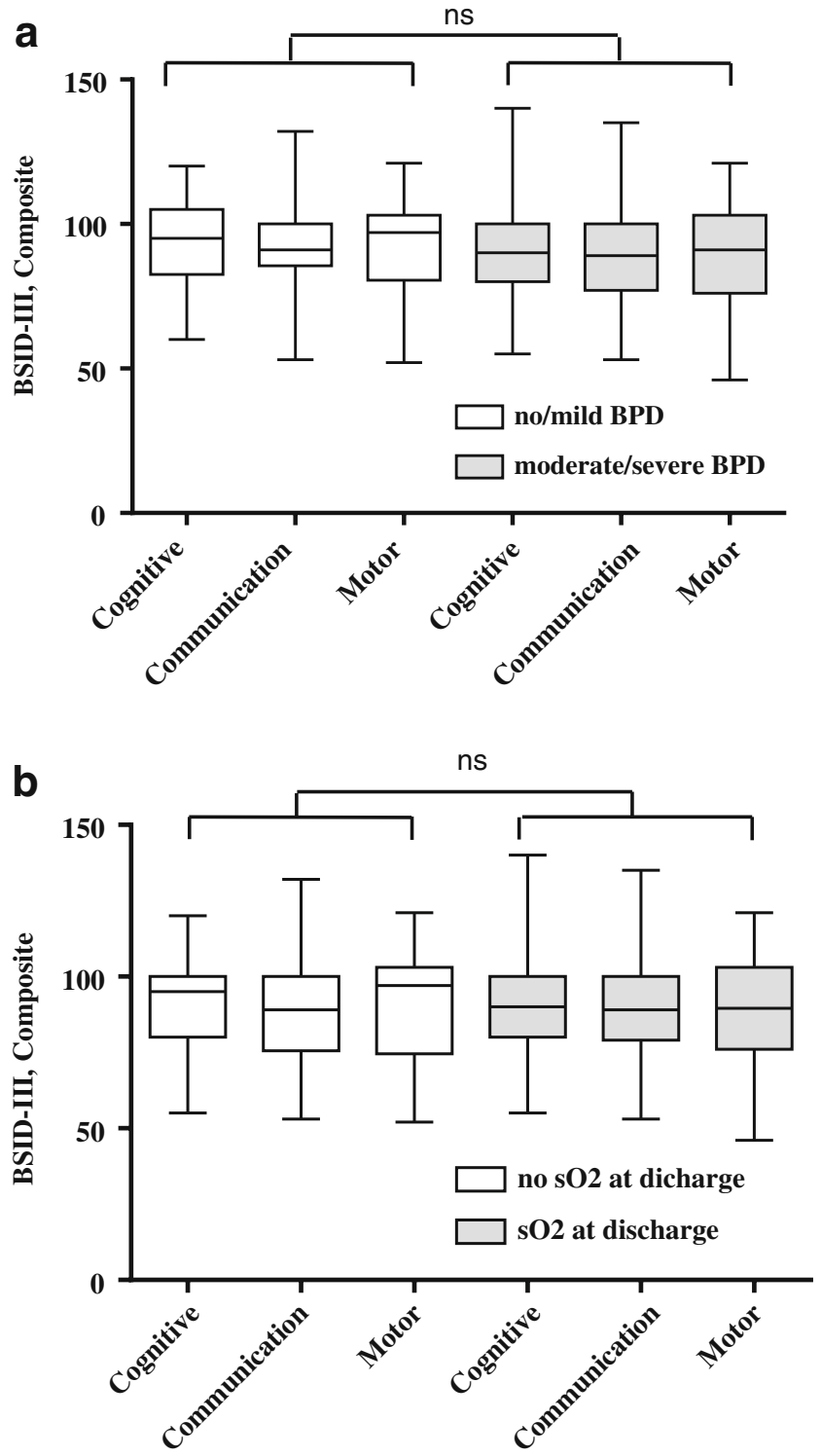

Fig. 2 BSID-III composite scores (cognitive, communication, and motor) of neonates born at $<27$ weeks gestation $(n=201)$. Boxplots represent median and interquartile range. a Boxplots comparing no/ mild BPD to those neonates with moderate/severe BPD. Student's $t$ test for cognitive score $(p=0.60)$, communication score $(p=0.53)$, and motor score $(p=0.19)$. There was no significant difference (ns) between the no/mild BPD and moderate/severe BPD groups. b Boxplots comparing no supplemental oxygen $\left(\mathrm{sO}_{2}\right)$ at discharge to those neonates receiving $\mathrm{SO}_{2}$ at discharge. Student's $t$ test for cognitive score $(p=0.58)$, communication score $(p=0.70)$, and motor score $(p=0.62)$. There was no significant difference (ns) between the no $\mathrm{sO}_{2}$ at discharge and $\mathrm{sO}_{2}$ at discharge groups

examined patient characteristics that might contribute to this finding. Patients diagnosed with surgical NEC and discharged home on room air had a significantly longer length of stay, as well as greater PMA at discharge, than those surgical NEC patients who were discharged on $\mathrm{sO}_{2}$. This suggests that in the subgroup of patients with surgical NEC, those discharged on room air remained in hospital longer, and during this longer hospital stay (an average of $\sim 7$ weeks) were able to wean from $\mathrm{sO}_{2}$.

The BSID-III was used to assess neurodevelopmental outcome. Recently, it has been suggested that the BSID-III underestimates the severity of disability as compared to the BSID-II [2, 19]. Therefore, we followed published recommendations and used a composite score of $<80$ on any of the three categories (cognitive, communication, or motor) or cerebral palsy to denote NDI [22]. Our rates of NDI were similar to a recent report by Moore et al. in the same gestational age group [22]. There was no significant difference in Bayley scores between those patients with no/mild BPD vs. moderate/severe BPD or those patients discharged on $\mathrm{sO}_{2}$ vs. room air for any of the three categories. Thus, BPD severity or need for $\mathrm{sO}_{2}$ at discharge in this cohort of patients does not adversely affect neurodevelopmental outcome. Although there is literature to suggest BPD predicts worsening NDI, many of these patients were evaluated prior to $2000[3,9,25]$. Other studies have suggested that BPD may not be an independent risk factor of poor neurodevelopmental outcome [13]. Our study population was evaluated between years 2004 and 2010 , so it may be that more recently there has been an improvement in neurodevelopmental outcome in patients with BPD. Consistent with this concept are at least three recent studies. Hintz et al. found worsening rates of BPD while NDI remained relatively constant over time [16]. The EPICure studies found that in the most recent patient cohort compared to earlier cohorts there were more neonates born at less than 27 weeks surviving without disability [21]. Finally, a recent systematic review of NDI rates in extremely preterm infants found a significant decrease in rates of cerebral palsy based on increasing year of birth [6].

At $\mathrm{NCH}$, we developed an innovative program directed at this population of extremely preterm infants, the Small Baby Program, that started on December 1, 2004 [23]. The adoption of this program which is based on a standardized approach to the care of these infants led to an improvement in hospital outcomes [23]. Furthermore, we found improved survival and neurodevelopmental outcomes at 18-24 months compared to similar cohorts of patients [23]. We also found at about the same time that the care given to patients with established moderate-to-severe BPD was highly variable and often lacked a neurodevelopmental focus during the initial NICU stay. Therefore, we implemented a standardized inpatient and outpatient program for these patients focused on developmental needs [29]. These programs may have impacted the favorable outcome that BPD patients in this study had who were discharged home on supplemental oxygen.

There are some notable limitations of our study. The population admitted to an all referral children's hospital may not be representative of all extremely preterm neonates. 
Table 3 Unadjusted and adjusted odds ratios for neurodevelopmental impairment (NDI) by patient characteristic

NDI defined as any Bayley composite score (cognitive, communication, or motor) $<80$ or $\mathrm{CP}$

\begin{tabular}{|c|c|c|c|c|c|c|}
\hline & \multicolumn{3}{|c|}{ Unadjusted } & \multicolumn{3}{|c|}{ Adjusted } \\
\hline & OR & $\mathrm{CI}$ & $p$ value & OR & $\mathrm{CI}$ & $p$ value \\
\hline$\leq 24$ weeks & 2.14 & $(1.26-3.63)$ & $<0.01$ & 1.88 & $(0.90-3.91)$ & 0.09 \\
\hline$\leq 700 \mathrm{~g}$ & 2.46 & $(1.45-4.17)$ & $<0.01$ & 1.70 & $(0.82-3.54)$ & 0.15 \\
\hline Apgar $5 \min \leq 3$ & 1.85 & $(0.86-4.0)$ & 0.12 & 1.85 & $(0.75-4.59)$ & 0.18 \\
\hline Admit dol $\geq 7$ & 0.82 & $(0.48-1.39)$ & 0.47 & 0.92 & $(0.46-1.82)$ & 0.80 \\
\hline CPAP $\geq 28$ days & 0.96 & $(0.57-1.64)$ & 0.89 & 1.42 & $(0.71-2.86)$ & 0.32 \\
\hline Ventilation $\geq 28$ days & 4.08 & $(2.28-7.32)$ & $<0.01$ & 3.21 & $(1.34-7.70)$ & 0.01 \\
\hline PDA ligation & 0.89 & $(0.53-1.48)$ & 0.64 & 0.63 & $(0.33-1.23)$ & 0.17 \\
\hline Surgical NEC & 3.68 & $(1.51-9.01)$ & $<0.01$ & 2.54 & $(0.83-7.78)$ & 0.10 \\
\hline Grade III-IV IVH & 4.90 & $(2.36-10.18)$ & $<0.01$ & 4.61 & $(1.8-11.8)$ & $<0.01$ \\
\hline Discharge at $>43$ weeks PMA & 3.22 & $(1.86-5.59)$ & $<0.01$ & 2.12 & $(1.04-4.32)$ & 0.04 \\
\hline Moderate-severe BPD & 1.49 & $(0.61-3.63)$ & 0.38 & 0.59 & $(0.16-2.16)$ & 0.43 \\
\hline Oxygen at discharge & 1.14 & $(0.62-2.09)$ & 0.67 & 0.52 & $(0.20-1.36)$ & 0.18 \\
\hline
\end{tabular}

For example, in our referral area, most extremely preterm infants are born in delivery hospitals with a level III NICU and are only transferred if there is need for surgical or subspecialty care. It should also be kept in mind that the extremely preterm neonates included in our study have survived both the delivery room and transport to our institution. We are an all referral center and therefore have limited ability to extract maternal data, as well as resuscitation data, from outside institutions for research purposes. Also, our study included information on 18-month Bayley scores; a recent systematic review found that higher rates of attrition were associated with worse neurodevelopmental outcome [15]. Although only $85 \%$ of our patients returned for follow-up, this is a relatively high follow-up rate for the USA [6] and improved follow-up would be expected to improve overall NDI. Lastly, at the time of this study, there was no policy in place to objectively measure the need for oxygen. However, since then, we have implemented a 36week oxygen challenge test and are following the data to determine if there is a decrease in the incidence of BPD and the use of supplemental oxygen at discharge.

The current definition of BPD depends on the need for and the amount of $\mathrm{sO}_{2}$ given to a patient [4-8]. Oxygen weaning varies by clinical practice among neonatologists and among centers. This may be responsible for some of the wide variation in BPD incidence among NICUs [10]. The currently used criteria for defining BPD results in the vast majority of patients born at $<27$ weeks having moderate-tosevere BPD. This is consistent with recent studies from the USA [6, 36], Norway [12], and Sweden [11] in a similar gestational age cohort. Further studies are needed to develop BPD phenotypes more specific to the extremely preterm infant that could be used to more effectively and efficiently develop preventative strategies and predict neonatal outcomes.
In summary, we report for the first time that the need for $\mathrm{sO}_{2}$ at discharge is not an independent predictor of poor neurodevelopmental outcome in patients born before 27 completed weeks gestational age. When examining variables that might predict discharge on supplemental oxygen, not unexpectedly long-term mechanical ventilation was the most predictive of discharge home on $\mathrm{sO}_{2}$ in this population. These findings underscore the need to develop strategies and therapies that decrease the length of time that mechanical ventilation is required to improve pulmonary outcomes in these patients. Given that the diagnosis of BPD is based on supplemental oxygen requirement, our data suggest that in the extremely preterm infant BPD as currently defined is found in nearly all patients. Therefore, we suggest that for the neonate born at the edge of viability there is a need for developing phenotypic criteria for BPD in order to better characterize disease severity and predict long-term outcomes. The data from this relatively large and recent cohort of extremely preterm infants demonstrate that discharge home on supplemental oxygen does not in and of itself translate to a poor neurodevelopmental outcome.

Acknowledgments The authors would like to thank Elizabeth Martin, Pamela Moorehead, John Hitchner, and the research staff of the Ohio Perinatal Research Network for their work to complete the data collection for this analysis. We would also like to thank the staff of the Small Baby Pod, Neonatology follow-up Clinics, and the Comprehensive Center for BPD at Nationwide Children's Hospital for their meticulous record keeping and their continued dedication to improving long-term neurodevelopmental outcome for our smallest patients.

Ethical standards All human studies have been approved by the appropriate ethics committee and have therefore been performed in accordance with the ethical standards laid down in the 1964 Declaration of Helsinki and its later amendments. 
Conflict of interest The authors declare that they have no conflict of interest.

Open Access This article is distributed under the terms of the Creative Commons Attribution License which permits any use, distribution, and reproduction in any medium, provided the original author(s) and the source are credited.

\section{References}

1. American Academy of Pediatrics Committee on Fetus and Newborn (2012) Levels of neonatal care. Pediatrics 130:587-597

2. Anderson PJ, De Luca CR, Hutchinson E, Roberts G, Doyle LW (2010) Underestimation of developmental delay by the new Bayley-III scale. Arch Pediatr Adolesc Med 164:352-356

3. Anderson PJ, Doyle LW (2006) Neurodevelopmental outcome of bronchopulmonary dysplasia. Semin Perinatol 30:227-232

4. Bancalari E, Claure N (2006) Definitions and diagnostic criteria for bronchopulmonary dysplasia. Semin Perinatol 30:164-170

5. Bancalari E, Claure N, Sosenko IR (2003) Bronchopulmonary dysplasia: changes in pathogenesis, epidemiology and definition. Semin Neonatol 8:63-71

6. Baraldi E, Carraro S, Filippone M (2009) Bronchopulmonary dysplasia: definitions and long-term respiratory outcome. Early human development 85:S1-3

7. Bhandari A, Bhandari V (2009) Pitfalls, problems, and progress in bronchopulmonary dysplasia. Pediatrics 123:1562-1573

8. Ehrenkranz RA, Walsh MC, Vohr BR, Jobe AH, Wright LL, Fanaroff AA, Wrage LA, Poole K (2005) Validation of the National Institutes of Health consensus definition of bronchopulmonary dysplasia. Pediatrics 116:1353-1360

9. Ehrenkranz RA, Walsh MC, Vohr BR, Jobe AH, Wright LL, Fanaroff AA, Wrage LA, Poole K, National Institutes of Child Health and Human Development Neonatal Research Network (2005) Validation of the National Institutes of Health consensus definition of bronchopulmonary dysplasia. Pediatrics 116:1353-1360

10. Ellsbury DL, Acarregui MJ, McGuinness GA, Klein JM (2002) Variability in the use of supplemental oxygen for bronchopulmonary dysplasia. J Pediatr 140:247-249

11. EXPRESS (2010) Incidence of and risk factors for neonatal morbidity after active perinatal care: extremely preterm infants study in Sweden (EXPRESS). Acta Paediatr 99:978-992

12. Farstad T, Bratlid D, Medbo S, Markestad T (2011) Bronchopulmonary dysplasia-prevalence, severity and predictive factors in a national cohort of extremely premature infants. Acta Paediatr 100:53-58

13. Gray PH, Burns YR, Mohay HA, O'Callaghan MJ, Tudehope DI (1995) Neurodevelopmental outcome of preterm infants with bronchopulmonary dysplasia. Arch Dis in Child Fetal Neonatal Ed 73:F128-134

14. Gray PH, O'Callaghan MJ, Rogers YM (2004) Psychoeducational outcome at school age of preterm infants with bronchopulmonary dysplasia. J Paediatrics Child Health 40:114-120

15. Guillen U, DeMauro S, Ma L, Zupancic J, Roberts R, Schmidt B, Kirpalani H (2012) Relationship between attrition and neurodevelopmental impairment rates in extremely preterm infants at 18 to 24 months: a systematic review. Arch Pediatr Adolesc Med 166:178-184

16. Hintz SR, Kendrick DE, Vohr BR, Poole WK, Higgins RD, National Institute of Child Health and Human Development Neonatal Research Network (2005) Changes in neurodevelopmental outcomes at 18 to 22 months' corrected age among infants of less than 25 weeks' gestational age born in 1993-1999. Pediatrics 115:1645-1651
17. Hughes CA, O'Gorman LA, Shyr Y, Schork MA, Bozynski ME, McCormick MC (1999) Cognitive performance at school age of very low birth weight infants with bronchopulmonary dysplasia. JDBP 20:1-8

18. Jobe AH, Bancalari E (2001) Bronchopulmonary dysplasia. Am J Respir Crit Care Med 163:1723-1729

19. Lowe JR, Erickson SJ, Schrader R, Duncan AF (2012) Comparison of the Bayley II Mental Developmental Index and the Bayley III Cognitive Scale: are we measuring the same thing? Acta Paediatr 101:e55-58

20. Mayes L, Perkett E, Stahlman MT (1983) Severe bronchopulmonary dysplasia: a retrospective review. Acta Paediatr Scand 72:225-229

21. Moore T, Hennessy EM, Myles J, Johnson SJ, Draper ES, Costeloe KL, Marlow N (2012) Neurological and developmental outcome in extremely preterm children born in England in 1995 and 2006: the EPICure studies. BMJ 345:e7961

22. Moore T, Johnson S, Haider S, Hennessy E, Marlow N (2012) Relationship between test scores using the second and third editions of the Bayley scales in extremely preterm children. J Pediatr 160:553-558

23. Moorehead PAEM, Shepherd EG, Parikh NA, Reagan PB, Gardner W, Yeates KO, Nelin LD (2012) Factors associated with survival of $<27$-week infants in an all-referral neonatal intensive care unit. J of Neonatal-Perinatal Med 5:105-111

24. Nankervis CA, Martin EM, Crane ML, Samson KS, Welty SE, Nelin LD (2010) Implementation of a multidisciplinary guidelinedriven approach to the care of the extremely premature infant improved hospital outcomes. Acta Paediatr 99:188-193

25. Natarajan G, Pappas A, Shankaran S, Kendrick DE, Das A, Higgins RD, Laptook AR, Bell EF, Stoll BJ, Newman N, Hale EC, Bara R, Walsh MC (2012) Outcomes of extremely low birth weight infants with bronchopulmonary dysplasia: impact of the physiologic definition. Early Human Dev 88:509-515

26. Northway WH Jr, Rosan RC, Porter DY (1967) Pulmonary disease following respirator therapy of hyaline-membrane disease. Bronchopulmonary dysplasia. N Engl J Med 276:357-368

27. O'Shea TM, Goldstein DJ, deRegnier RA, Sheaffer CI, Roberts DD, Dillard RG (1996) Outcome at 4 to 5 years of age in children recovered from neonatal chronic lung disease. Dev Med Child Neurol 38:830-839

28. Robertson CM, Etches PC, Goldson E, Kyle JM (1992) Eight-year school performance, neurodevelopmental, and growth outcome of neonates with bronchopulmonary dysplasia: a comparative study. Pediatrics 89:365-372

29. Schmidt B, Asztalos EV, Roberts RS, Robertson CM, Sauve RS, Whitfield MF, Trial of Indomethacin Prophylaxis in Preterms (TIPP) Investigators (2003) Impact of bronchopulmonary dysplasia, brain injury, and severe retinopathy on the outcome of extremely low-birthweight infants at 18 months: results from the trial of indomethacin prophylaxis in preterms. JAMA 289:1124-1129

30. Shepherd EG, Knupp AM, Welty SE, Susey KM, Gardner WP, Gest AL (2012) An interdisciplinary bronchopulmonary dysplasia program is associated with improved neurodevelopmental outcomes and fewer rehospitalizations. J Perinatol 32:33-38

31. Short EJ, Klein NK, Lewis BA, Fulton S, Eisengart S, Kercsmar C, Baley J, Singer LT (2003) Cognitive and academic consequences of bronchopulmonary dysplasia and very low birth weight: 8-yearold outcomes. Pediatrics 112:e359

32. Singer L, Yamashita T, Lilien L, Collin M, Baley J (1997) A longitudinal study of developmental outcome of infants with bronchopulmonary dysplasia and very low birth weight. Pediatrics 100:987-993

33. Singer LT, Siegel AC, Lewis B, Hawkins S, Yamashita T, Baley J (2001) Preschool language outcomes of children with history of bronchopulmonary dysplasia and very low birth weight. JDBP 22:19-26 
34. Skidmore MD, Rivers A, Hack M (1990) Increased risk of cerebral palsy among very low-birthweight infants with chronic lung disease. Dev Med and Child Neurology 32:325-332

35. Stahlman MT (1979) Clinical description of bronchopulmonary dysplasia. J Pediatr 95:829-834

36. Stoll BJ, Hansen NI, Bell EF, Shankaran S, Laptook AR, Walsh MC, Hale EC, Newman NS, Schibler K, Carlo WA, Kennedy KA, Poindexter BB, Finer NN, Ehrenkranz RA, Duara S, Sanchez PJ, O'Shea TM, Goldberg RN, Van Meurs KP, Faix RG, Phelps DL, Frantz ID 3rd, Watterberg KL, Saha S, Das A, Higgins RD (2010) Neonatal outcomes of extremely preterm infants from the NICHD Neonatal Research Network. Pediatrics 126:443-456

37. Taeusch H, Ballard R, Gleason C (2005) Avery's diseases of the newborn, 8th edn. Elsevier, Philadelphia
38. Vohr BR, Coll CG, Lobato D, Yunis KA, O'Dea C, Oh W (1991) Neurodevelopmental and medical status of low-birthweight survivors of bronchopulmonary dysplasia at 10 to 12 years of age. Dev Med Child Neurol 33:690-697

39. Vohr BR, Stephens BE, Higgins RD, Bann CM, Hintz SR, Das A, Newman JE, Peralta-Carcelen M, Yolton K, Dusick AM, Evans PW, Goldstein RF, Ehrenkranz RA, Pappas A, Adams-Chapman I, Wilson-Costello DE, Bauer CR, Bodnar A, Heyne RJ, Vaucher YE, Dillard RG, Acarregui MJ, McGowan EC, Myers GJ, Fuller J, Eunice Kennedy Shriver National Institute of Child Health and Human Development Neonatal Research Network (2012) Are outcomes of extremely preterm infants improving? Impact of Bayley assessment on outcomes. J Pediatr 161(222-228):e223 